\title{
Hexamine adsorption study on activated carbon from aqueous solutions for application in treatment of hexamine industrial wastewater
}

\author{
M. Taghdiri $\cdot$ N. Zamani
}

Received: 11 June 2011/Revised: 2 September 2011/Accepted: 17 January 2012/Published online: 31 July 2012

(C) CEERS, IAU 2012

\begin{abstract}
The adsorption of hexamine onto powdered activated carbon from aqueous solutions was studied in a fixed bed system. Langmuir, Freundlich, Redlich-Peterson and Toth isotherm models were used to fit the experimental data and isotherm parameters were determined. The results revealed that the adsorption isotherm models fitted the data in the order of Langmuir $>$ Toth $>$ Redlich-Peterson $>$ Freundlich. Lagergren pseudo-first order kinetic model was found to correlate well with the experimental data. The effects of solution $\mathrm{pH}$, temperature, initial hexamine concentration and added salts concentration on the adsorption capacity and the rate of adsorption were studied. The results indicate that the rate of adsorption increases and then decreases as temperature of the hexamine solution increases, however, the adsorption capacity decreases. The addition of low concentration of salt significantly increases the adsorption capacity of activated carbon. The results showed that the activated carbon has potential for the adsorption of hexamine from industrial hexamine wastewater.
\end{abstract}

Keywords Amine - Carbon powder - Adsorption isotherms · Kinetic

\section{Taghdiri $(\bowtie)$}

Department of Chemistry,

Payame Noor University,

19395-3697 Tehran, Iran

e-mail: mehditaghdiri@yahoo.com

\section{N. Zamani}

Department of Applied Chemistry,

Faculty of Sciences, University of Semnan,

Semnan, Iran

\section{Introduction}

Activated carbon is the most common solid phase extraction material used for the removal of organic and inorganic compounds (Bansal and Goyal 2005; Cabal et al. 2009; Gur-Reznik et al. 2008; McDonough et al. 2008; Onundi et al. 2010; Yapsakl et al. 2009; Yu et al. 2009). Activated carbon is known to have a heterogeneous physical and chemical structure. It is characterized by the existence of micro, meso, and macro pores of different sizes, while its surface indicates hydrophobic characteristics. Activated carbon structure consists of graphene layers between which slit-shaped pores are formed. The acidic, basic, neutral or oxidative/reductive nature of the activated carbon surface is the result of the presence of heteroatoms such as $\mathrm{H}, \mathrm{S}, \mathrm{O}$, and $\mathrm{N}$, which usually exist in the form of organic functional groups (Boehm 1994). Adsorption of amines on activated carbon in aqueous phase has been less studied (Cooney and Wijaya 1987; Seidel and Radeke 1990). A number of studies related to the adsorption of amine gases such as ammonia, methyl amine, dimethyl amine and trimethyl amine have been conducted using activated carbon (Tanada et al. 1985; Tanada et al. 1988; Tsutomu et al. 2004). Hexamine or methenamine or urotropine, $\left(\mathrm{CH}_{2}\right)_{6} \mathrm{~N}_{4}$, is a non-aromatic heterocyclic amine with a symmetrical three-dimensional molecular structure, as shown in Fig. 1. It is a white, crystalline powder with a slight amine odor, soluble in water $\left(867 \mathrm{~g} / \mathrm{L}\right.$ at $\left.25^{\circ} \mathrm{C}\right)$, alcohol, and chloroform, but it is insoluble in ether and has a melting point of $280{ }^{\circ} \mathrm{C}$. The acidic dissociation constant $\left(K_{\mathrm{a}}\right)$ of hexamine is about $10^{-5}$ (Strom and Jun 1986) and $\mathrm{pH}$ of $10 \%$ aqueous solution is 8-9. Hexamine is used for the production of plastic materials, explosives, phenolic resins, antibacterial pharmaceutics (as a urinary tract antiseptic), disinfecting materials, in the rubber industry as an additive, 


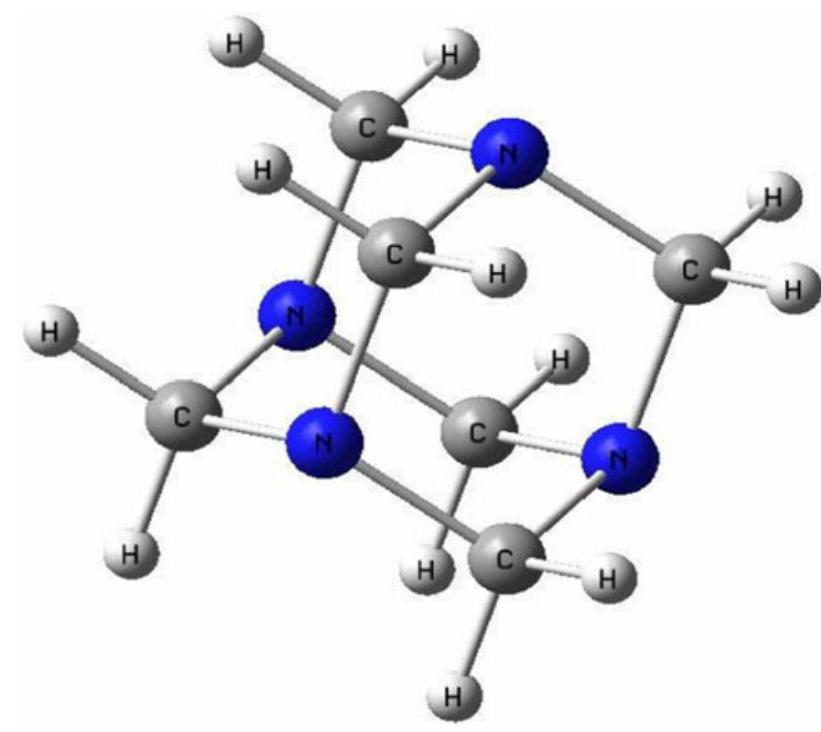

Fig. 1 The molecular structure of hexamine

etc. The most common production method of hexamine in industrial scale is the reaction of formaldehyde with ammonia or ammonium salts. This reaction produces considerable amount of heat and water (Alamdari and Tabkhi 2004). Hexamine wastewater that is formed in the production of hexamine usually contains residual amounts of hexamine and ammonium. The wastewater is initially dosed with sodium hydroxide to raise the solution $\mathrm{pH}$ to 11 or higher to convert ammonium ions to ammonia gas. The steam stripper separates the ammonia from the solution. Hexamine has a very stable structure which made the molecule recalcitrant to oxidation via methylotrophic pathway reactions so that very few microorganisms in soil can break it to utilize as sole source of carbon, nitrogen and energy (Middelhoven and van Doesburg 2007).

Therefore, hexamine is resistant to biodegradation (Kaszycki and Koloczek 2002), even when sludge has been acclimated for a long period (Hutnan et al. 2005) and it must be considered as a real wastewater pollutant and should not be allowed to enter water resources and soils. The high strength hexamine-containing wastewater is efficiently removed from industrial wastewater by means of a cation exchange resin (Rafati et al. 2010; Saadatjou et al. 2010). This method requires an expensive cation exchanger resin and remains the trace amounts of hexamine in wastewater. Therefore, it is necessary to adsorb the remaining hexamine with a complement method.

This work addresses the adsorption of hexamine solution on powder-activated carbon under a wide range of operating conditions with a combination of experimental and modeling studies. Equilibrium isotherm parameters are used to describe the experimental sorption data. Isotherm parameters are determined using the method of non-linear least squares. Kinetic parameters are then evaluated and are correlated with process variables such as solution $\mathrm{pH}$, temperature of solution, initial concentration and added inorganic salt concentration.

It is the object of the present study to evaluate adsorption of hexamine by means of activated carbon which is available at an industrially low cost for possible application in treatment of hexamine industrial wastewater. Hexamine wastewater is formed in the production factories of hexamine. It is also produced from the petrochemical factories (Ting et al. 2007).

This research was carried out in Research and Development Department of Sina Chemical Industries Company, Shiraz, Iran, and was completed in October 2010.

\section{Materials and methods}

Apparatus

Weighing of materials was performed using an analytical balance model Sartorius MCBA 100 with precision of \pm 0.0001 g. A Shimadzu spectrophotometer model $160 \mathrm{U}$ was used for spectrophotometric measurement of hexamine. For $\mathrm{pH}$ measurements, a Metrohm type $691 \mathrm{pH}-$ meter was used.

\section{Chemicals}

Ethyl acetoacetate, $n$-propanol, sodium chloride, potassium iodide and sodium phosphate buffer were purchased from Merck and were of analytical grade. The hexamine powder (99.5 \%) was from Sina Chemical Industries Co. (Iran). It was recrystallized from ethanol and dried at $60{ }^{\circ} \mathrm{C}$ to constant weight and used for preparation of standard solutions of hexamine. The activated carbon powder type YL-200-II was used for adsorbing of hexamine. Characteristics of activated carbon are shown in Table 1. The usable fraction of activated carbon was prepared by boiling in distilled water for $30 \mathrm{~min}$, cooling and settling then washing three times in distilled water to remove fines and impurities that may have desorbed from the activated carbon. All activated carbon samples were then placed in glass drying pars and dried in an oven at $105{ }^{\circ} \mathrm{C}$ for $24 \mathrm{~h}$ and were used after cooling.

Table 1 Properties of activated carbon used in the investigation

\begin{tabular}{lllll}
\hline Type & $\begin{array}{l}\text { Surface } \\
\text { area } \\
\left(\mathrm{m}^{2} / \mathrm{g}\right)\end{array}$ & $\begin{array}{l}\text { Average pore } \\
\text { diameter } \\
(\mathrm{nm})\end{array}$ & $\begin{array}{l}\text { Particle } \\
\text { size 200 } \\
\text { mesh }(\%)\end{array}$ & $\begin{array}{l}\text { Iodine } \\
\text { number }\end{array}$ \\
\hline YL-200-II & 920 & 2.0 & $\geq 90$ & 900 \\
\hline
\end{tabular}




\section{Procedures}

\section{Adsorption studies}

Aqueous-phase adsorption of hexamine on activated carbon was conducted by placing $50 \mathrm{~mL}$ hexamine solution in contact with $1 \mathrm{~g}$ activated carbon packed in a fixed bed glass column having an inner diameter of $2 \mathrm{~cm}$ under different operating conditions of inlet solution concentration, period of contact time of hexamine and activated carbon, temperature of hexamine solution, hexamine solution $\mathrm{pH}$ and added salt concentrations. In all experiments, a control sample of hexamine solution was used without activated carbon to eliminate possible adsorption of hexamine on glass column. Then, the remaining hexamine concentration in the eluate was measured spectrophotometrically and was compared with the amount obtained for control sample.

In the equilibrium studies, a constant adsorbent dose was used while the initial solution concentration was varied. The equilibrium isotherms were determined at $\mathrm{pH} 13$ and at temperature of $5^{\circ} \mathrm{C}$. The equilibrium time for adsorption of hexamine was determined to be $60 \mathrm{~min}$. The procedures of kinetic experiments were identical to those of equilibrium tests. The aqueous samples were taken at preset time intervals, and the concentrations of hexamine were measured. The detail conditions of experiments are shown in the figure legends.

\section{Determination of hexamine}

An accurately weighed quantity of hexamine was dissolved in distilled water to prepare a stock solution $(1,000 \mathrm{mg} / \mathrm{L})$. Experimental solutions of the desired concentrations were obtained by successive dilutions. Determination of hexamine was performed based on the absorption measurement of Hantzsch ethyl ester, formed upon reacting ethyl acetoacetate with hexamine, using a UV-spectrophotometer at $370 \mathrm{~nm}$ (Balasubramanian et al. 2003). The calibration curve for hexamine was linear from 1 to $130 \mathrm{mg} / \mathrm{L}$ $\left(R^{2}=0.99\right)$. The remaining concentration of hexamine in the eluate was determined based on the prepared calibration curve.

The amount of hexamine adsorbed onto the sorbent in $\mathrm{mg} / \mathrm{g}$ at time, $t$ was calculated using the following equation:

$q_{t}=\frac{\left(C_{0}-C_{t}\right) V}{m}$

where $C_{t}$ is the concentration of hexamine in the solution at a given time in $\mathrm{mg} / \mathrm{L}, C_{0}$ is initial hexamine concentration in $\mathrm{mg} / \mathrm{L}, m$ is the amount of sorbent mass in grams, and $V$ is the solution volume in $\mathrm{L}$.
Mathematical modeling

The isotherm and kinetic models were used to describe the sorption data generated from hexamine sorption by activated carbon. The isotherm and kinetic models parameters were determined by non-linear error functions minimizing using the solver add-in with Microsoft's spreadsheet, Excel. Chi-square statistic and the residual root mean square error (RMSE) were used to evaluate the fitness of isotherm and kinetic equations to the experimental data. The Chi-square test statistic is the sum of the squares of the differences between the experimental data and data obtained by calculating from models. The equivalent mathematical statement is:

$\chi^{2}=\sum_{i=1}^{N} \frac{\left(q_{\mathrm{e}, \mathrm{exp} .}-q_{\mathrm{e}, \mathrm{calc} .}\right)^{2}}{q_{\mathrm{e}, \text { calc. }}}$,

where $q_{\text {e,exp. }}$ and $q_{\text {e,calc. }}$ are the equilibrium capacity obtained by experimental data and calculating from the model in $\mathrm{mg} / \mathrm{g}$, respectively. If data from the model are similar to the experimental data, $\chi^{2}$ will be a small number; if they are different, $\chi^{2}$ will be a large number. It is better to also analyze the data set using RMSE to confirm the best fit isotherm for the sorption system. RMSE can be defined as follows:

$\mathrm{RMSE}=\sqrt{\frac{1}{N-2} \sum_{i=1}^{N}\left(q_{\mathrm{e}, \text { exp. }}-q_{\mathrm{e}, \mathrm{calc} .}\right)^{2}} \times 100$.

\section{Results and discussion}

Adsorption isotherm models

Equilibrium isotherm equations are used to describe the experimental sorption data. The equation parameters and the underlying thermodynamic assumptions of these equilibrium models often provide some insight into the sorption mechanisms and the surface properties and affinities of the sorbent. The most common isotherms for describing solidliquid sorption systems are the Langmuir, the Freundlich, the Redlich-Peterson and the Toth isotherms.

The Freundlich isotherm (Freundlich 1906), the earliest known relationship describing the sorption equation, was applied for the adsorption data at equilibrium time. This empirical isotherm based on sorption onto heterogeneous surface is expressed by the following equation:

$q_{\mathrm{e}}=K_{\mathrm{F}} C_{\mathrm{e}}^{1 / n}$,

where $C_{\mathrm{e}}$ is the equilibrium concentration in $\mathrm{mg} / \mathrm{L}$ and $q_{\mathrm{e}}$ is the amount of hexamine adsorbed per unit mass of the adsorbent in $\mathrm{mg} / \mathrm{g} . K_{\mathrm{F}}$ is considered as the capacity factor 


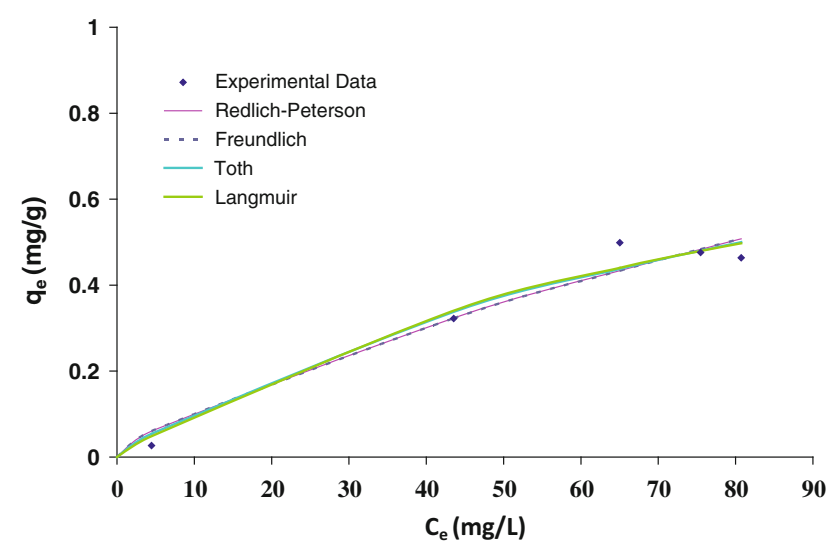

Fig. 2 Langmuir, Freundlich, Redlich-Peterson and Toth isotherms for the adsorption of hexamine by activated carbon $(V=50 \mathrm{~mL}$, sorbent dosage $=1 \mathrm{~g}, \mathrm{pH}=13$ and $T=5{ }^{\circ} \mathrm{C}$ )

Table 2 Parameters of the isotherm models for the adsorption of hexamine onto activated carbon

\begin{tabular}{llcll}
\hline Model & Parameter & Value & $\chi^{2}$ & RMSE \\
\hline Langmuir & $q_{\mathrm{m}}$ & 1.080 & 0.021 & 3.678 \\
& $K_{\mathrm{a}}$ & 0.011 & & \\
Freundlich & $K_{\mathrm{F}}$ & 0.020 & 0.033 & 4.318 \\
& $1 / n$ & 0.736 & & \\
Redlich-Peterson & $A$ & 0.129 & 0.032 & 4.295 \\
& $B$ & 5.569 & & \\
\multirow{3}{*}{ Toth } & $g$ & 0.285 & & \\
& $K_{t}$ & 0.066 & 0.026 & 3.893 \\
& $a_{t}$ & 23.193 & & \\
& $1 / t$ & 0.509 & & \\
\hline
\end{tabular}

of the adsorbent in $(\mathrm{mg} / \mathrm{g})(\mathrm{mg} / \mathrm{L})^{n}$ while the exponential term $1 / n$ represents the heterogeneity of the adsorption surface and is related to the magnitude of the adsorption driving force (El-Sayed and Bandosz 2003).

Figure 2 shows the experimental aqueous-phase adsorption isotherms for hexamine/activated carbon system at temperature solution of $5{ }^{\circ} \mathrm{C}$ along with the curve fitted by Freundlich isotherm model. The Freundlich parameters are also shown in Table 2.

The Langmuir (Langmuir 1916) equation which is valid for monolayer sorption onto a surface with a finite number of identical sites is given by Eq. (5):

$q_{\mathrm{e}}=\frac{q_{\mathrm{m}} K_{\mathrm{a}} C_{\mathrm{e}}}{1+K_{\mathrm{a}} C_{\mathrm{e}}}$,

where $q_{\mathrm{m}}$ is the maximum amount of adsorbed hexamine per unit mass of sorbent when the saturation is attained, $K_{\mathrm{a}}$ is the Langmuir constant related to the energy of adsorption in $\mathrm{L} / \mathrm{mg}$. Figure 2 shows the experimental data and the non-linear curve fitting by Langmuir model. The parameter of the model, $q_{\mathrm{m}}$ and $K_{\mathrm{a}}$, is listed in Table 2 .

The Redlich-Peterson isotherm (Redlich and Peterson 1959) contains three parameters and involves the features of both the Langmuir and the Freundlich isotherms. It can be described as follows:

$q_{\mathrm{e}}=\frac{A C_{\mathrm{e}}}{1+B C_{\mathrm{e}}^{\mathrm{g}}}$

Three isotherm parameters, $A, B$ and $g(0<g<1)$, were evaluated using solver tool of Excel software and are presented in Table 2. Figure 2 shows the experimental data and the non-linear curve fitting by Redlich-Peterson model.

Toth isotherm has proven useful in describing sorption in heterogeneous systems such as phenolic compounds on carbon (Ho et al. 2002). It can be represented by the following equation:

$q_{\mathrm{e}}=\frac{K_{t} C_{\mathrm{e}}}{\left(a_{t}+C_{\mathrm{e}}\right)^{1 / t}}$

Examination of isotherm plots (Fig. 2) shows Langmuir and Toth isotherm more accurately describe the sorption behavior of hexamine on activated carbon. Since the method used to derive the isotherm parameters minimizes the Chi-square statistic and RMSE, the Langmuir and Toth isotherms exhibit low values that they produces a better fit.

The values of maximum adsorption capacity $\left(q_{\mathrm{m}}\right)$ and $K_{\mathrm{a}}$ determined using Langmuir model are $1.080 \mathrm{mg} / \mathrm{g}$ and $0.011 \mathrm{~L} / \mathrm{mg}$, respectively. The value of $K_{\mathrm{a}}$ is the constant representing the affinity of sorbate to sorbent. The adsorption data obeyed both Langmuir and Toth models exhibiting heterogeneous surface conditions and monolayer adsorption. The Langmuir model generally represents chemisorption on a set of well-defined localized adsorption sites having the same adsorption energy, independent of surface coverage and with no interaction between adsorbed molecules (Behera et al. 2008; Ncibi et al. 2007). It seems that the chemisorption process is dominant over the physical process in the adsorption of hexamine onto activated carbon since there is a sharing of the electron pairs of the nitrogen atoms of hexamine with the surface of activated carbon.

The Freundlich exponent, $1 / n$, should have values lying in the range of $0.1-1$ for classification as favorable adsorption (Freundlich 1906) and it has been shown that this value between 0.1 and 0.5 indicates beneficial adsorption (Mckay et al. 1982). The value of $1 / n$ for the adsorption of most organic compounds by activated carbon is less than 1 . When $1 / n$ is close to 1 (steep slopes) (in the case of hexamine is 0.736 ), it indicates a high adsorptive capacity at high equilibrium liquid phase concentrations and rapidly diminishing capacities at lower equilibrium 
Table 3 Pseudo-first order sorption kinetic model constants at various $\mathrm{pH}$ conditions

\begin{tabular}{lllll}
\hline $\mathrm{pH}$ & 8 & 11 & 13 & 14 \\
\hline$q_{\mathrm{e}}(\mathrm{mg} / \mathrm{g})$ & 0.123 & 0.175 & 0.192 & 0.193 \\
$k_{1}\left(\mathrm{~min}^{-1}\right)$ & 0.038 & 0.084 & 0.133 & 0.209 \\
$\chi^{2}$ & 0.0044 & 0.0017 & 0.00001 & 0.000003 \\
RMSE & 1.346 & 1.216 & 0.117 & 0.054 \\
\hline
\end{tabular}

Table 4 Pseudo-first order sorption kinetic model constants at different temperatures of hexamine solution

\begin{tabular}{lllllll}
\hline $\begin{array}{l}\text { Temperature } \\
\left({ }^{\circ} \mathrm{C}\right)\end{array}$ & 5 & 10 & 15 & 20 & 40 & 60 \\
\hline$q_{\mathrm{e}}(\mathrm{mg} / \mathrm{g})$ & 0.276 & 0.241 & 0.216 & 0.191 & 0.139 & 0.127 \\
$k_{1}\left(\mathrm{~min}^{-1}\right)$ & 0.121 & 0.125 & 0.169 & 0.142 & 0.078 & 0.035 \\
$\chi^{2}$ & 0.0008 & 0.0006 & 0.0002 & 0.003 & 0.0003 & 0.0001 \\
$\mathrm{RMSE}$ & 0.104 & 0.822 & 0.463 & 0.551 & 0.475 & 0.235 \\
\hline
\end{tabular}

Table 5 Pseudo-first order sorption kinetic model constants at different initial concentrations of hexamine

\begin{tabular}{lllllll}
\hline $\begin{array}{l}\text { Initial } \\
\text { concentration } \\
\text { of hexamine } \\
(\mathrm{mg} / \mathrm{L})\end{array}$ & 5 & 20 & 50 & 75 & 85 & 90 \\
\hline$q_{\mathrm{e}}(\mathrm{mg} / \mathrm{g})$ & 0.027 & 0.114 & 0.315 & 0.512 & 0.494 & 0.480 \\
$k_{1}\left(\mathrm{~min}^{-1}\right)$ & 0.128 & 0.143 & 0.112 & 0.133 & 0.093 & 0.100 \\
$\chi^{2}$ & 0.00003 & 0.0003 & 0.0016 & 0.0041 & 0.0015 & 0.0043 \\
$\mathrm{RMSE}$ & 0.069 & 0.434 & 1.564 & 3.247 & 1.897 & 3.199 \\
\hline
\end{tabular}

concentrations. The adsorption system approaches to chemical process and distances from physical process whatever the value of $n$ approaches to unity and below unity (Behera et al. 2008). The value of $n$ in this system (1.36) represents the adsorption process is combination of chemisorption as dominant and physical adsorption.
As it is observed from Fig. 2 and Table 2, the value of $\mathrm{g}$ in the Redlich-Peterson isotherm is much smaller than 1 , which means the isotherm has been approached the Freundlich but not the Langmuir isotherm. The Chisquare statistic and RMSE values are presented in Table 2, indicating that the Freundlich and RedlichPeterson models showed lower correlation with the experimental adsorption data compared to the Langmuir model.

\section{Adsorption kinetic model}

For evaluating the adsorption kinetic of hexamine, the Lagergren pseudo-first order kinetic model was used that is expressed as Eq. (8) (Annadurai et al. 2002):

$q_{t}=q_{\mathrm{e}}-q_{\mathrm{e}} 10^{\frac{-k_{1} t}{2.303}}$

where $q_{t}$ and $q_{\mathrm{e}}$ are the amount of hexamine adsorbed (mg/g) at any time and equilibrium time, respectively, and $k_{1}$ is the rate constant in $\min ^{-1} . q_{\mathrm{e}}$ and $k_{1}$ were determined in various hexamine solution $\mathrm{pH}$, temperature of hexamine solution, initial solution concentration and added salt concentration.

Adsorption kinetic study of hexamine shows that Lagergren equation could fit well over the range of contact times and describe the rated of hexamine sorption onto activated carbon in various conditions. As can be seen from Tables 3, 4, 5 and 6, the values of Chi-square statistic and RMSE of the pseudo-first order Lagergren model are very low.

\section{Effect of solution $\mathrm{pH}$}

To investigate the role of surface chemistry of activated carbon on the adsorption capacity of hexamine, the effect of solution $\mathrm{pH}$ was studied. The experiments were carried out by varying the initial $\mathrm{pH}$ from 8 to 14 , under a constant
Table 6 Pseudo-first order sorption kinetic model constants at different concentrations of added salts

\begin{tabular}{llllll}
\hline $\begin{array}{l}\text { Concentration of } \\
\text { added salt }(\mathrm{M})\end{array}$ & $1 \times 10^{-4}$ & $2 \times 10^{-4}$ & $3 \times 10^{-4}$ & $4 \times 10^{-4}$ & $5 \times 10^{-4}$ \\
\hline $\begin{array}{l}q_{\mathrm{e}}(\mathrm{mg} / \mathrm{g}) \\
\mathrm{NaCl}\end{array}$ & 1.072 & 1.043 & 1.021 & 0.896 & 0.679 \\
$\mathrm{KI}$ & 1.073 & 1.034 & 1.011 & 0.899 & 0.670 \\
$k_{1}\left(\mathrm{~min}^{-1}\right)$ & & & & & \\
$\mathrm{NaCl}$ & 0.186 & 0.170 & 0.129 & 0.139 & 0.122 \\
$\mathrm{KI}$ & 0.184 & 0.158 & 0.130 & 0.144 & 0.110 \\
$\chi^{2}$ & & & & \\
$\mathrm{NaCl}$ & 0.0003 & 0.00006 & 0.0018 & 0.0016 & 0.0007 \\
$\mathrm{KI}$ & 0.00009 & 0.00008 & 0.00225 & 0.00133 & 0.00008 \\
$\mathrm{RMSE}$ & & & & & 1.505 \\
$\mathrm{NaCl}$ & 1.285 & 0.585 & 3.061 & 2.661 & 0.536 \\
$\mathrm{KI}$ & 0.717 & 0.654 & 3.368 & 2.449 & \\
\hline
\end{tabular}




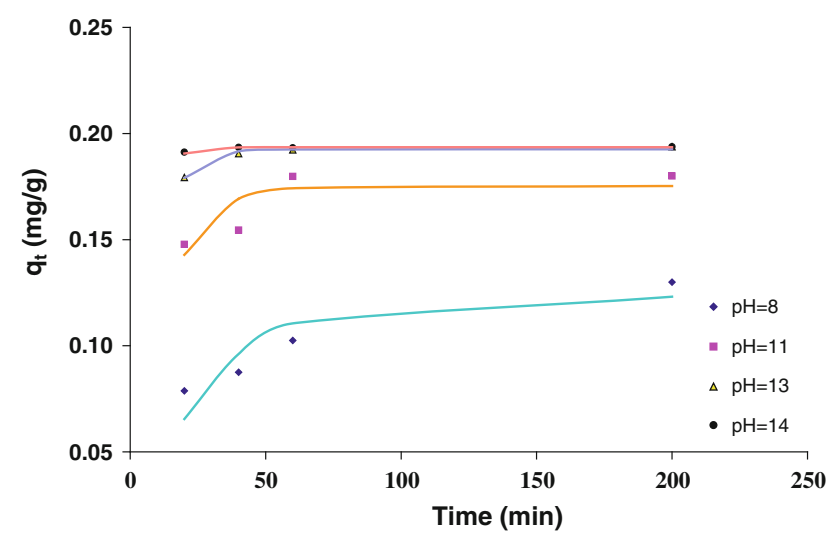

Fig. 3 Pseudo-first order sorption kinetics of hexamine onto activated carbon at various $\mathrm{pH}$ conditions. The solid lines indicate the fit to Lagergren kinetic model $\left(C_{0}=50 \mathrm{mg} / \mathrm{L}, V=50 \mathrm{~mL}\right.$, sorbent dosage $=1 \mathrm{~g}$ and $T=25^{\circ} \mathrm{C}$ )

initial hexamine concentration of $50 \mathrm{mg} / \mathrm{L}$, and activated carbon dosage of $1 \mathrm{~g}$. The acidic $\mathrm{pHs}$ were not studied because hexamine is hydrolyzed to formaldehyde and ammonia under acidic conditions (Hutnan et al. 2005). The experimental data and fitted experimental data by kinetic model are shown in Fig. 3. The kinetic model parameters and their corresponding Chi-square and RMSE values are shown in Table 3.

The effect of solution $\mathrm{pH}$ on the adsorption of hexamine (Fig. 3) shows the amount of adsorption increases when the $\mathrm{pH}$ is increased. Similar results of $\mathrm{pH}$ effect were also reported for the adsorption of amine bases including aniline $\left(\mathrm{p} K_{\mathrm{a}}=4.63\right), \mathrm{m}$-phenylenediamine ( $\mathrm{p} K_{\mathrm{a}}{ }^{\prime} \mathrm{s}=2.65$ and 4.88) and quinine $\left(\mathrm{p} K_{\mathrm{a}}{ }^{\prime} \mathrm{s}=4.2\right.$ and 8.8) on activated carbon (Cooney and Wijaya 1987). The $\mathrm{p} K_{\mathrm{a}}$ of hexamine is 5.05 (Strom and Jun 1986). It can be concluded that the neutral form of hexamine adsorbs more extensively than its ionized form. The adsorption of $\alpha$-picoline $\left(\mathrm{p} K_{\mathrm{b}}=8.0\right)$ from aqueous solution has been studied at different $\mathrm{pHs}$ onto the activated carbon. It was observed that adsorption increased at $\mathrm{pH}>8$ (Seidel and Radeke 1990). The adsorption of hexamine also increased at $\mathrm{pH}>8$ that is close to the $\mathrm{p} K_{\mathrm{b}}$ of hexamine, 9.0. Therefore, it may be postulated that the more adsorption of weak amine bases can be attained at pHs greater than $\mathrm{p} K_{\mathrm{b}}$ of amine. The kinetic study showed increasing the $\mathrm{pH}$ value from 8 to 14 increased the adsorption rate of hexamine about 5.5 times (Table 3). Probably, the interactions of $\mathrm{Na}^{+}$cations from $\mathrm{NaOH}$ with hexamine molecules increase the adsorption rate of hexamine toward the negatively charged carbon surface and hence, the adsorption capacity increases. In the real wastewater, the $\mathrm{pH}$ of solution after removal of ammonium by $\mathrm{NaOH}$ is greater than 11 and is sufficient for the adsorption of hexamine. This explanation is consistent with the chemisorption of hexamine.
Effect of temperature of hexamine solution

The dependence of the rate of adsorption and adsorption capacity on the temperature of hexamine solution is shown in Fig. 4. The values of $q_{\mathrm{e}}$ and $k_{1}$ are listed in Table 4.

The effect of temperature study showed a decrease of the adsorption capacity as temperature was increased from 5 to $60{ }^{\circ} \mathrm{C}$ and an increase of the rate of adsorption as temperature was increased from 5 to $15^{\circ} \mathrm{C}$ (Table 4). Usually, the adsorption process is combination of chemisorptions (most frequently irreversible adsorption) and physical adsorption (most probably reversible adsorption). Physical adsorption capacity decreases with increasing temperature due to breaking of weak bonds. Since the adsorption rate is diffusion limited process, the rate of adsorption of the organic from solution increases as the temperature increases. At higher temperatures, however, high heat energy to the molecule enables to break off the weak adsorption potential.

\section{Effect of initial concentration}

The experimental results of the sorption of hexamine from aqueous solutions at various initial concentrations on activated carbon are shown in Fig. 5. The non-linear pseudo-first order Lagergren models are also presented in Fig. 5. The parameters of kinetic model and their corresponding Chi-square and RMSE values are shown in Table 5. The equilibrium sorption capacity of activated carbon increased from 0.027 to $0.512 \mathrm{mg} / \mathrm{g}$ with an increase in the concentration of hexamine from 5 to $75 \mathrm{mg} / \mathrm{L}$ with an adsorbent dose of $1 \mathrm{~g}$ and $\mathrm{pH}$ of 13 . This is due to the acceleration of hexamine diffusion from solutions at higher concentrations (Ozacar 2003; Sun and Xu 1997).

\section{Effect of added salts concentrations}

The effect of adding $1 \times 10^{-4}-5 \times 10^{-4} \mathrm{M} \mathrm{NaCl}$ and $\mathrm{KI}$ salts to solutions of hexamine at $\mathrm{pH} 13$ prior to adsorption onto activated carbon are shown in Figs. 6 and 7, respectively. The values of $q_{\mathrm{e}}$ and $k_{1}$, obtained from the fitting of experimental data by kinetic model (Eq. 8) and their corresponding Chi-square and RMSE values, are listed in Table 6.

The results found from the effect of added salt showed the presence of salt significantly increased the adsorption capacity and rate of adsorption of hexamine onto activated carbon as the salt was added in the concentrations of less than $3 \times 10^{-4} \mathrm{M}$ to hexamine solution (Table 6). At the high $\mathrm{pH}$ of 13 , at which the adsorption studies were conducted, the carbon surface is negatively charged (Arafat et al. 1999) and hexamine $\left(\mathrm{p} K_{\mathrm{a}}=5.05\right)$ is neutral but containing partial negatively charged nitrogen atoms (due 


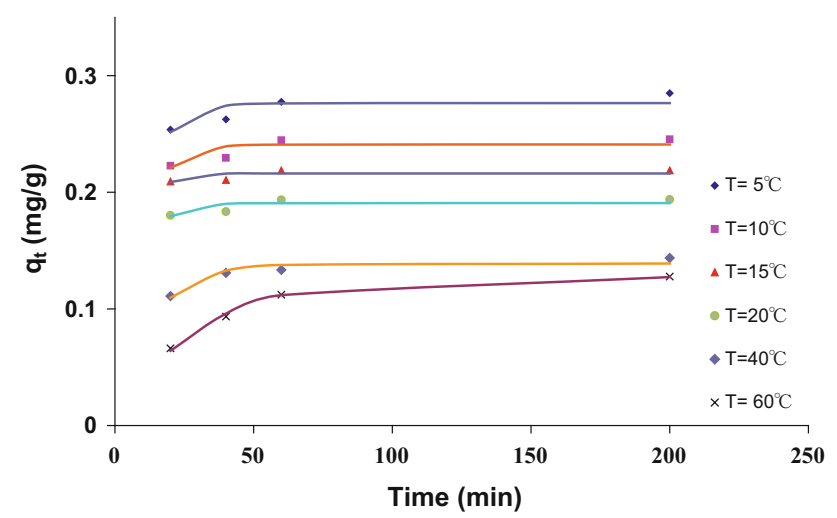

Fig. 4 Pseudo-first order sorption kinetics of hexamine onto activated carbon at different temperatures of hexamine solution. The solid lines indicate the fit to Lagergren kinetic model $\left(C_{0}=50 \mathrm{mg} / \mathrm{L}\right.$, $V=50 \mathrm{~mL}$, sorbent dosage $=1 \mathrm{~g}$ and $\mathrm{pH}=13$ )

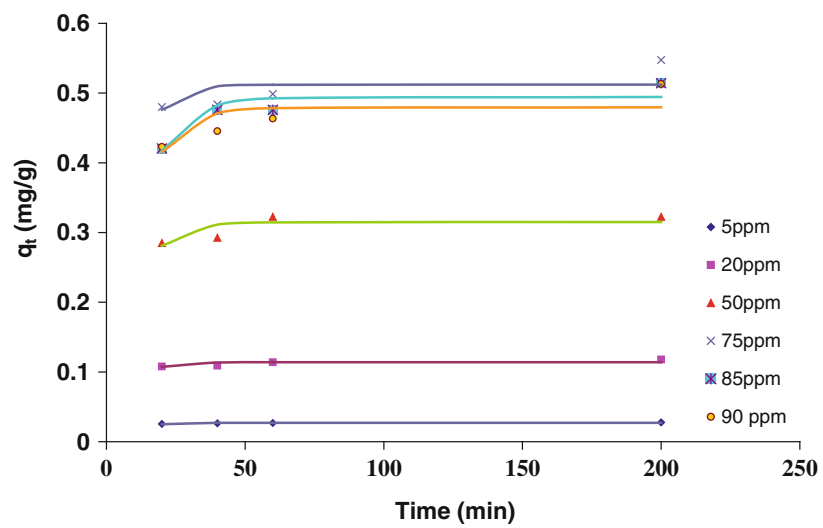

Fig. 5 Pseudo-first order sorption kinetics of hexamine onto activated carbon at different initial concentrations of hexamine. The solid lines indicate the fit to Lagergren kinetic model $(V=50 \mathrm{~mL}$, sorbent dosage $=1 \mathrm{~g}, \mathrm{pH}=13$ and $T=5{ }^{\circ} \mathrm{C}$ )

to the existence of the non-bonding electron pairs). The presence of cations in solution causes a partial neutralization of the negative charges on the carbon surface subsequently enabling it to adsorb more molecules of hexamine since the attractive forces are increased between the adsorbed cations and the partial negatively charged nitrogen atoms of hexamine. This explanation is consistent with the Langmuir model that implies the adsorption process is chemical. The adsorption capacity decreases with increasing salt concentration. This phenomenon has also been observed for adsorption of ibuprofen on activated carbon on adding $\mathrm{NaCl}$ salt at $\mathrm{pH} 3$ the adsorbate of which is neutral. The reason of this has been explained based on the reducing all the electrostatic interactions, both attractive and repulsive by increasing the ionic strength (i.e. increasing the salt concentration) of the solution (Behera et al. 2012).

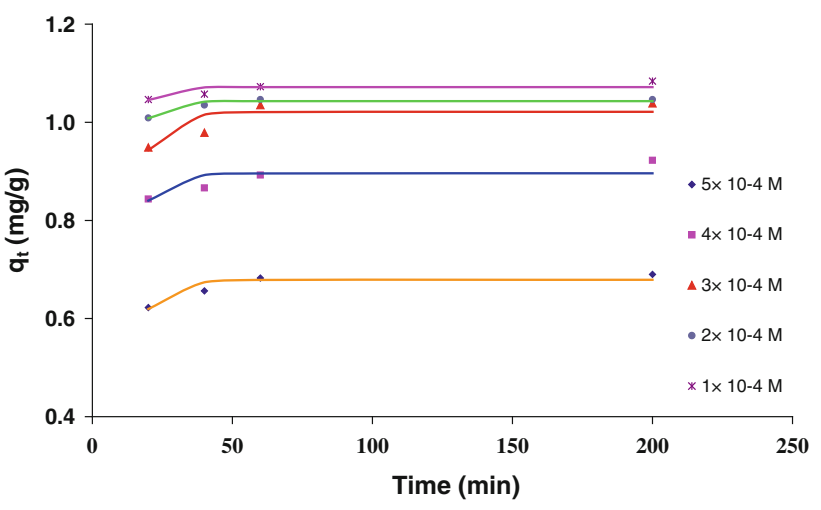

Fig. 6 Pseudo-first order sorption kinetics of hexamine onto activated carbon at different concentrations of $\mathrm{NaCl}$ as added salt. The solid lines indicate the fit to Lagergren kinetic model $\left(C_{0}=75 \mathrm{mg} / \mathrm{L}\right.$, $V=50 \mathrm{~mL}$, sorbent dosage $=1 \mathrm{~g}, \mathrm{pH}=13$ and $T=5^{\circ}$ )

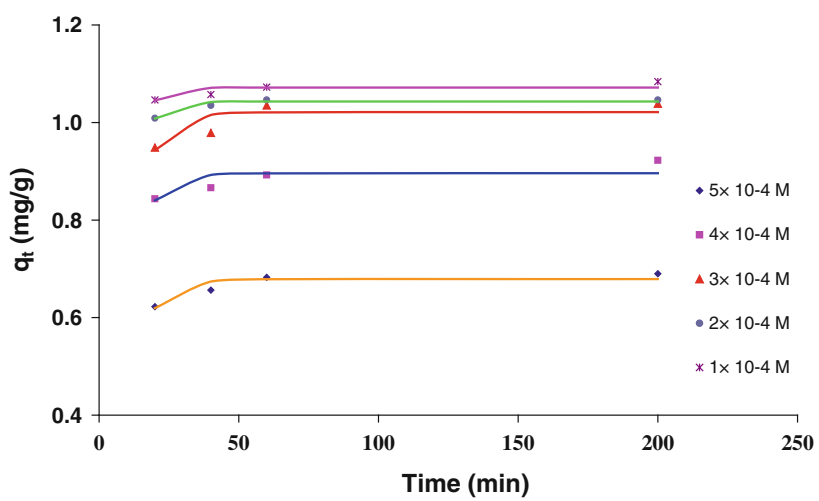

Fig. 7 Pseudo-first order sorption kinetics of hexamine onto activated carbon at different concentrations of $\mathrm{KI}$ as added salt. The solid lines indicate the fit to Lagergren kinetic model $\left(C_{0}=75 \mathrm{mg} / \mathrm{L}\right.$, $V=50 \mathrm{~mL}$, sorbent dosage $=1 \mathrm{~g}, \mathrm{pH}=13$ and $T=5{ }^{\circ} \mathrm{C}$ )

\section{Conclusion}

The results of the present investigation showed that the activated carbon has potential for the adsorption of hexamine and can be a low-cost sorbent for removing low concentrations of hexamine from industrial hexamine wastewater. The present work suggests that the temperature, $\mathrm{pH}$ solution and added salt concentration ranges during practical use can be changed accordingly on good or poor performances of the adsorbent. The addition of low concentration of salt significantly increases the adsorption capacity of activated carbon in adsorbing hexamine from aqueous solutions.

Acknowledgments The authors express their appreciation to Sina Chemical Industries Company and Payame Noor University for support of this study. 


\section{References}

Alamdari A, Tabkhi F (2004) Kinetics of hexamine crystallization in industrial scale. Chem Eng Process 43(7):803-810

Annadurai G, Juang RS, Lee DJ (2002) Use of cellulose-based wastes for adsorption of dyes from aqueous solutions. J Hazard Mater 92(3):263-274

Arafat HA, Franz M, Pinto NG (1999) Effect of salt on the mechanism of adsorption of aromatics on activated carbon. Langmuir 15(18):5997-6003

Balasubramanian M, Thennarasu S, Sudhakaran T, Perumal PT (2003) Spectrophotometric and fluorimetric determination of hexamine in pure form and its pharmaceutical formulation. Biol Pharm Bull 26(8):1211-1214

Bansal RC, Goyal M (2005) Activated carbon adsorption. Taylor and Francis Group, London, pp 351-353

Behera SK, Kim JH, Guo X, Park HS (2008) Adsorption equilibrium and kinetics of polyvinyl alcohol from aqueous solution on powdered activated carbon. J Hazard Mater 153(3):1207-1214

Behera SK, Oh SY, Park HS (2012) Sorptive removal of ibuprofen from water using selected soil minerals and activated carbon. Int J Environ Sci Technol 9:85-94

Boehm H (1994) Some aspects of the surface chemistry of carbon blacks and other carbons. Carbon 32(5):759-769

Cabal B, Ania C, Parra J, Pis J (2009) Kinetics of naphthalene adsorption on an activated carbon: comparison between aqueous and organic media. Chemosphere 76(4):433-438

Cooney DO, Wijaya J (1987) Effect of $\mathrm{pH}$ and added salts on the adsorption of ionizable organic species onto activated carbon from aqueous solution. In: Proc. 2nd Eng. Found. Conf. Fundam. Adsorpt, pp 185-194

El-Sayed Y, Bandosz TJ (2003) Effect of increased basicity of activated carbon surface on valeric acid adsorption from aqueous solution activated carbon. Phys Chem Chem Phys 5(21):4892-4898

Freundlich H (1906) ber die adsorption in läsungen. Z Phys Chem $57: 385-470$

Gur-Reznik S, Katz I, Dosoretz CG (2008) Removal of dissolved organic matter by granular-activated carbon adsorption as a pretreatment to reverse osmosis of membrane bioreactor effluents. Water Res 42(6-7):1595-1605

Ho YS, Porter JF, McKay G (2002) Equilibrium isotherm studies for the sorption of divalent metal ions onto peat: copper, nickel and lead single component systems. Water Air Soil Pollut 141:1-33

Hutnan M, Drtil M, Derco J, Mrafkova L (2005) Biodegradation of hexamethylenetetramine in anaerobic baffled reactor. Pol J Environ Stud 14(5):585-591

Kaszycki P, Koloczek H (2002) Biodegradation of formaldehyde and its derivatives in industrial wastewater with methylotrophic yeast Hansenula polymorpha and with yeast-augmented activated sludge. Biodegradation 13(2):91-99

Langmuir I (1916) The constitution and fundamental properties of solids and liquids. Part I. Solids. J Am Chem Soc 38(11):2221-2295

McDonough KM, Fairey JL, Lowry GV (2008) Adsorption of polychlorinated biphenyls to activated carbon: equilibrium isotherms and a preliminary assessment of the effect of dissolved organic matter and biofilm loadings. Water Res 42(3):575-584

Mckay G, Blair H, Gardner J (1982) Adsorption of dyes on chitin. I. Equilibrium studies. J Appl Polymer Sci 27(8):3043-3057

Middelhoven WJ, van Doesburg W (2007) Utilization of hexamethylenetetramine (urotropine) by bacteria and yeasts. Antonie Leeuwenhoek 91(2):191-196

Ncibi MC, Mahjoub B, Seffen M (2007) Adsorptive removal of textile reactive dye using Posidonia oceanica (L.) fibrous biomass. Int J Environ Sci Tech 4(4):433-440

Onundi YB, Mamun AA, Al Khatib MF, Ahmed YM (2010) Adsorption of copper, nickel and lead ions from synthetic semiconductor industrial wastewater by palm shell activated carbon. Int J Environ Sci Technol 7(4):751-758

Ozacar M (2003) Phosphate adsorption characteristics of alunite to be used as a cement additive. Cem Concr Res 33:1583-1587

Rafati L, Mahvi AH, Asgari AR, Hosseini SS (2010) Removal of chromium (VI) from aqueous solutions using Lewatit FO36 nano ion exchange resin. Int J Environ Sci Technol 7(1):147-156

Redlich O, Peterson DL (1959) A useful adsorption isotherm. J Phys Chem 63(6):1024-1024

Saadatjou N, Taghdiri M, Farrokhi R (2010) Removal of urotropine from industrial wastewater by acidic cation exchange resins. Iran J Environ Health Sci Eng 7(4):345-352

Seidel A, Radeke KH (1990) Effect of pH on adsorption equilibria for dissolved weak organic electrolytes on activated carbon. Acta Hydrochim Hydrobiol 18(6):691-699

Strom JG, Jun HW (1986) Separation and quantitation of methenamine in urine by ion-pair extraction. J Pharma Sci 75(4):416-420

Sun G, Xu X (1997) Sunflower stalks as adsorbents for color removal from textile wastewater. Ind Eng Chem Res 36:808-812

Tanada S, Boki K, Ohtani N, Yamasaki R (1985) Steric effect in the adsorption of ammonia and trimethylamine into micropores of activated carbon. Chem Pharm Bull 33(2):837-841

Tanada S, Tsutusi S, Boki K, Nakamura T (1988) Adsorption behavior of ammonia and trimethylamine binary mixtures in pores of plasma-treated activated carbon. Eisei Kagaku 34(2):156-160

Ting WP, Huang YH, Lu MC (2007) Catalytic treatment of petrochemical wastewater by electroassisted fenton technologies. React Kinet Catal Lett 92(1):41-48

Tsutomu I, Takashi A, Kuniaki K, Kikuo O (2004) Comparison of removal efficiencies for ammonia and amine gases between woody charcoal and activated carbon. J Health Sci 50(2):148-153

Yapsakl K, Çeçen F, Akta Ö, Can ZS (2009) Impact of surface properties of granular activated carbon and preozonation on adsorption and desorption of natural organic matter. Environ Eng Sci 26(3):489-500

Yu Z, Peldszus S, Huck PM (2009) Adsorption of selected pharmaceuticals and an endocrine disrupting compound by granular activated carbon. 1. Adsorption capacity and kinetics. Environ Sci Tech 43(5):1467-1473 